\title{
Identification of Differentially Expressed Genes Related to Intramuscular Fat Development in the Early and Late Fattening Stages of Hanwoo Steers
}

\author{
Seung-Hwan Lee ${ }^{1, \#}$, Eung-Woo Park ${ }^{1, \#}$, Yong-Min Cho' ${ }^{1}$, Sung-Kon Kim ${ }^{1}$, Jun-Heon Lee ${ }^{2}$, Jin-Tae Jeon ${ }^{4}$, \\ Chang-Soo Lee ${ }^{3}$, Seok-Ki Im¹, Sung-Jong Oh$^{1}$, J. M. Thompson ${ }^{5}$ and Duhak Yoon ${ }^{1, *}$ \\ ${ }^{1}$ Animal Genomics \& Bioinformatics Division, National Livestock Research Institute, RDA, Suwon 441-305, Korea \\ ${ }^{2}$ Division of Animal Science and Resources, Research Center for Transgenic Cloned Pigs, Chungnam National University, Daejeon 305-764, Korea \\ ${ }^{3}$ Department of Applied Biochemistry, Kon-Kuk University, Chungju 380-710, Korea \\ ${ }^{4}$ Department of Animal science, Kyeongsang National University, Jin-ju 660-701, Korea \\ ${ }^{5}$ School of Rural Science and Natural Resources, The University of New England, Armidale, NSW 2351, Australia
}

Received 21 November 2006, Accepted 9 April 2007

\begin{abstract}
Marbling of cattle meat is dependent on the coordinated expression of multiple genes. Cattle dramatically increase their intramuscular fat content in the longissimus dorsi muscle between 12 and 27 months of age. We used the annealing control primer (ACP)-differential display RTPCR method to identify differentially expressed genes (DEGs) that may participate in the development of intramuscular fat between early (12 months old) and late fattening stages (27 months old). Using 20 arbitrary ACP primers, we identified and sequenced 14 DEGs. BLAST searches revealed that expression of the MDH, PI4-K, ferritin, ICER, NID-2, WDNMI, telethonin, filamin, and desmin (DES) genes increased while that of GAPD, COP VII, ACTA1, CamK II, and nebulin decreased during the late fattening stage. The results of functional categorization using the Gene Ontology database for 14 known genes indicated that MDH, GAPD, and COP VII are involved in metabolic pathways such as glycolysis and the TCA cycle, whereas telethonin, filamin, nebulin, desmin, and ACTA1 contribute to the muscle contractile apparatus, and PI4-K, CamK II, and ICER have roles in signal transduction pathways regulated by growth factor or hormones. The final three genes, NID-2, WDNMI, and ferritin, are involved in iron transport and extracellular protein inhibition. The expression patterns were confirmed for seven genes (MDH, PI4-K, ferritin, ICER, nebulin, WDNMI, and telethonin) using real-time PCR. We found that the novel transcription repressor ICER gene was
\end{abstract}

${ }^{\#}$ These authors are equally contributed to this work.

*To whom correspondence should be addressed.

Tel: 82-31-290-1593; Fax: 82-31-290-1602

E-mail: dhyoon@rda.go.kr highly expressed in the late fattening stage and during bovine preadipocyte differentiation. This information may be helpful in selecting candidate genes that participate in intramuscular fat development in cattle.

Keywords: ACP DD-RT-PCR, Differential Expressed Genes (DEGs), Intramuscular fat

\section{Introduction}

Meat quality is determined by meat color, fat color, texture, and marbling (intramuscular fat) scores. Marbling plays a particularly important role in determining the juiciness and tenderness of beef, and is one of the main factors used to determine beef quality grade in the United States (USDA, 1989), Japan (JMGA, 1988), and Korea. Thus, marbling is a very important and valuable trait in the beef cattle industry.

Intramuscular fat is accumulated in the perimysial connective tissue surrounding the myofiber bundles (Moody et al., 1968). Excess energy intake results in lipid deposition in adipose tissue and skeletal muscle (Krebs and Roden, 2005). A specific gene expression pattern may initiate and maintain cell differentiation and proliferation during adipogenesis in muscle tissue. Studies using 3T3 L1 preadipocytes have reported that the differentiation of preadipocytes into adipocytes induces gene expression of two transcription factors, CCAAT/enhancer binding protein (C/EBP) and peroxisome proliferator-activated receptor (PPAR), which are triggered by adipogenic inducers such as insulin, dexamethasone, long-chain fatty acids, and retinoids (Ailhaud et al., 1992; Chawla, 1994; MacDougald and Lane, 1995; Wu et al., 1996; Tang and Lane, 1999).

A high-energy diet and extending periods of fattening time 
increase intramuscular fat content and cause excessive external lipid deposition such as the accumulation of subcutaneous adipose tissue and abdominal fat. Thus, the characterization of gene-related muscle-specific adipogenesis is very important in the beef cattle industry. Several recent reports have used gene expression profiling with cDNA microarray analysis and ddRT-PCR to identify marbling regulator genes (Child et al., 2002; Wang et al., 2005). However, no study has identified a key regulator related to adipogenesis within the longissimus dorsi muscle.

Cattle begin adipogenesis during the early fattening stage that takes place over the first 12 months of life, and then develop intramuscular fat during the late fattening stage, which ends at 27 months. Therefore, the discovery and characterization of bovine genes that are differentially expressed between the early and late fattening stages would be a useful tool for the identification of an intramuscular fat regulator in muscle. Here we have identified 14 differentially expressed genes (DEGs) in the early and late fattening stages in cattle using the ddRT-PCR method, and analyzed the expression patterns of seven DEGs during the differentiation of bovine intramuscular preadipocytes using a real time RT-PCR assay.

\section{Materials and Methods}

Animals, diet and sampling. Eight Hanwoo male were selected at 1 month old with the similar birth weight $(24.8 \pm 3.8 \mathrm{~kg})$ and castrated at 3 months old. All steers were fed the same diets in a feedlot house. The concentrates were offered at $1.5 \%$ and $1.8 \%$ of body weight on growing ( $\sim 6$ months) and early fattening stage (6 12 months), respectively, and in late fattening stage (13 27 months), steers were fed high concentrate grain diet ad libitum. Steers were fed forage ad libitum and had free access to fresh water during the whole period. The animal were humanely killed at 12 $(n=4)$, and 27 months old $(n=4)$ at the slaughter house of NLRI (National Livestock Research Institite), respectively. All muscle samples were taken at the same position of longissimus dorsi between $5^{\text {th }}$ and $6^{\text {th }}$ lumbar vertebrae of steers. And, a various samples (liver, longissimus dorsi, rump and subcutaneous adipose tissue) were also taken. All samples were immediately frozen in liquid nitrogen and stored at $-80^{\circ} \mathrm{C}$ until analysis.

Bovine intramuscular preadipocyte cell culture. Bovine intramuscular preadipocyte was collected from 12 month old Hanwoo steers by sterile dissection following rapid decapitation (Lee et al., 2005). To differentiate of bovine intramuscular preadipocyte, the preadipocyte cells were cultured in Dulbecco's Modified Eagle's medium (DMEM) containing 10\% FBS, $0.25 \mu \mathrm{M}$ dexamethasone (Sigma), $33 \mu \mathrm{M}$ biotin, $17 \mu \mathrm{M}$ pantothenate, $1 \mathrm{mM}$ carpylic acid, $200 \mu \mathrm{M}$ ascorbic acid, $10 \mu \mathrm{g} / \mathrm{ml}$ insulin, $10 \mathrm{mM}$ acitic acid, $0.5 \mathrm{mM}$ 3-isobutyl-1-methylantine. The differentiation media was introduced following confluence and the media changed every 2 days until day 10 of culture.

Total RNA extraction. The total RNA samples were prepared from longissimus dorsi for the ddRT-PCR prescreening and bovine preadipocyte cell line, for the gene expression analysis during differentiation of bovine intramuscular preadipocyte cell using Trizol reagent (Life Technologies Inc.) according to the manufacturer's instructions and quantified by absorbance at $260 \mathrm{~nm}$.

ACP-based differential display RT-PCR. First-strand cDNA synthesis was performed for $1.5 \mathrm{~h}$ at $42^{\circ} \mathrm{C}$ in a final reaction volume of $20 \mu \mathrm{l}$ containing purified total RNA $3 \mu \mathrm{g}, 4 \mu \mathrm{l}$ of 5reaction buffer, $5 \mu \mathrm{l}$ dNTPs (each $2.5 \mathrm{mM}$ ), $2 \mu \mathrm{l}$ of $10 \mu \mathrm{m}$ cDNA synthesis primer dT-ACP1, $0.5 \mu \mathrm{l}$ of RNAase Inhibitor ( $40 \mathrm{U} / \mu \mathrm{l}$; Promega) and $1 \mu \mathrm{l}$ superscript II reverse transcriptase (200 U/ $\mu \mathrm{l}$; Invitrogen). The synthesized first-strand cDNA samples were diluted by the addition of $100 \mu \mathrm{l}$ ultra-purified water. Polymerase chain reaction (PCR) amplification was conducted using the same GeneFishing ${ }^{\mathrm{TM}}$ DEG kits (Seegene) in $50 \mu$ reaction volume, consisting of 10 buffer without $\mathrm{MgCl}_{2}, 25 \mathrm{mM} \mathrm{MgCl}, 5 \mu \mathrm{m}$ arbitrary ACPs, $10 \mu \mathrm{m}$ dT-ACP2, $2 \mathrm{mM}$ dNTP, $2.5 \mathrm{U}$ Taq DNA polymerase (applied biosystems) and $1 \mu \mathrm{l}$ of first-strand cDNA, using a PTC 225 DNA engine (Biorad). Each kit comprises 20 different arbitrary annealing control primers. The program of PCR amplification was 1 cycle at $94^{\circ} \mathrm{C}$ for $5 \mathrm{~min}, 50^{\circ} \mathrm{C}$ for $3 \mathrm{~min}$ and $72^{\circ} \mathrm{C}$ for $1 \mathrm{~min}, 40$ cycles at $94^{\circ} \mathrm{C}$ for $40 \mathrm{~s}, 65^{\circ} \mathrm{C}$ for $40 \mathrm{~s}, 72^{\circ} \mathrm{C}$ for $40 \mathrm{~s}$ and $72^{\circ} \mathrm{C}$ for $5 \mathrm{~min}$. The PCR products were separated by $2 \%$ agarose gel. The bands were photographed using Polaroid film under ultraviolet light after ethidium bromide staining and analyzed.

Cloning and sequence analysis. Differentially expressed bands were extracted and cloned into a TOPO TA cloning vector (Invitrogen). To confirm the identities of insert DNA, isolated plasmids were sequenced using a ABI3730XL sequencer (Applied Biosystems). Complete sequences were analyzed by searching for similarities using a BLASTX program (Altschul et al., 1990) at the National Center for Biotechnology Information (NCBI).

Quantitative real-time PCR confirmation for selected genes. In this study, we identified 14 differentially expressed genes in early (12 month) and later (27 month) fattening stage. Of these genes, we selected 7 differentially expressed genes to validate ACP ddRTPCR prescreening. To characterize a degree of intramuscular fat development between early and late fattening stages, we selected the two adipocyte specific marker genes such as $\mathrm{C} / \mathrm{EBP} \alpha$ and PPAR $\gamma$. The candidate genes for ACP ddRT-PCR analysis validation were phosphatidyl inositol 4-kinase (PI4-K), Inducible cAMP early repressor (ICER), calmodulin-dependent protein kinase II (CamK II), Ferritin, Telethonin, Nebulin and WDNM1 protein precursor. First strand cDNA was synthesized from $3 \mu \mathrm{g}$ total RNA pooled from each four individual animal using the random hexamer primers (Promega Co.) and the superscript reverse transcriptase enzyme (Invitrogen Co.). The mRNA expression levels for the adipocyte specific marker and selected genes were analysed by quantitative real-time PCR with specific primer (Table 1). 18S rRNA gene (GenBank Accession No. AY779626) was used as an internal control. Realtime RT-PCR amplification mixtures $(20 \mu \mathrm{l})$ contained $1 \mu \mathrm{l}$ cDNA, 2SYBR Green I Master Mix (10 $\mu \mathrm{l})$ (Qiagen., GmbH, Germany), and $10 \mathrm{pM}$ forward and reverse primers. The real-time PCR reactions started at $95^{\circ} \mathrm{C}$ for $15 \mathrm{~min}$ for predenaturation, and the condition was set at $95^{\circ} \mathrm{C}$ for $10 \mathrm{~s}, 56^{\circ} \mathrm{C}$ for $20 \mathrm{~s}$ and $72^{\circ} \mathrm{C}$ for $30 \mathrm{~s}$. The PCR cycle performed 40 cycles. The 
PCR were conducted in Rotor-Gene 3000 system (Corbett research Co., Australia). The relative quantification of target genes expression were evaluated using the $\Delta \Delta \mathrm{C}_{\mathrm{T}}$ method. The $\Delta \mathrm{C}_{\mathrm{T}}$ value was determined by subtracting the $18 \mathrm{~S}$ ribosomal $\mathrm{C}_{\mathrm{T}}$ value for each sample from the target $C_{T}$ value. The $\Delta \Delta C_{T}$ was calculated by subtracting the early fattening stage (12 month old) $\Delta \mathrm{C}_{\mathrm{T}}$ value from the late fattening stage (27 month old) $\Delta \mathrm{C}_{\mathrm{T}}$ value. Fold change in the relative gene expression of target were determined by calculating the $2^{-\Delta \Delta C T}$.

Gene expression analysis during preadipocyte differentiation for selected genes. To analyze gene expression pattern of the 7 selected genes during preadipocyte differentiation, we extracted total RNA from cultured cells and synthesized a $1^{\text {st }} \mathrm{cDNA}$ from the extracted RNAs. Real-time RT-PCR amplification mixtures $(20 \mu \mathrm{l})$ contained $1 \mu \mathrm{l}$ cDNA, 2SYBR Green I Master Mix $(10 \mu \mathrm{l})$ (Qiagen., $\mathrm{GmbH}$, Germany), and $10 \mathrm{pM}$ forward and reverse primers. The real-time PCR reactions started at $95^{\circ} \mathrm{C}$ for $15 \mathrm{~min}$ for predenaturation, and the condition was set at $95^{\circ} \mathrm{C}$ for $10 \mathrm{~s}, 56^{\circ} \mathrm{C}$ for $20 \mathrm{~s}$ and $72^{\circ} \mathrm{C}$ for $30 \mathrm{~s}$. The PCR cycle performed 40 cycles. The PCR were conducted in Rotor-Gene 3000 system (Corbett research Co., Australia). The relative quantification of target genes expression were evaluated using the $\Delta \Delta \mathrm{C}_{\mathrm{T}}$ method. The $\Delta \mathrm{C}_{\mathrm{T}}$ value was determined by subtracting the $18 \mathrm{~S}$ ribosomal $\mathrm{C}_{\mathrm{T}}$ value for each sample from the target $C_{T}$ value. Fold change in the relative gene expression of target were determined by calculating the $2^{-\mathrm{ACT}}$.

Statistical analysis. Results of realtime PCR analysis are given as means \pm SD. Statistical significance was determined using the Student's t-test in Fig. 2. The level of significance used in all studies was $P<0.05$. Treatment at different time intervals in Fig. 3 was analyzed by ANOVA. Significant differences were detected $(P<$
0.05) by Duncan's multiple range tests using a PC statistical package (SAS Institute Inc., 2002 Cary, NC ).

\section{Results}

Identification of DEGs between early and late fattening stages in cattle. We performed ACP ddRT-PCR to isolate any DEGs between the early and late fattening stages using a combination of 20 arbitrary primers and two anchored oligo (dT) primers from an ACP-based GeneFishing PCR kit (Seegen Inc.). A total of 14 DEG fragments were isolated from gels and sequenced. We identified nine upregulated candidate genes and five that were downregulated in the late fattening stage compared to the early fattening stage (Fig. 1). Gene Ontology annotations, BLASTN, and BLASTX searches of all 14 sequences against the GenBank database revealed that all of these DEGs have been well characterized in other species. The identified genes included: telethonin, nebulin, desmin, filamin, and actin 1 , which are related to the development of muscle and myofiber bundles, and glyceraldehyde-3phosphate dehydrogenase (GPDH), cytochrome $\mathrm{C}$ oxidase polypeptide VIIc (COP VIIc), and malate dehydrogenase 2 (MDH-2), which are related to metabolic pathways such as glycolysis and the TCA cycle. We also identified phosphatidyl inositol 4-kinase (PI4-K), induced cAMP Early Repressor (ICER), and calcium/calmodulin-dependent protein kinase II, which are involved in the phosphatidyl inositol cycle in relation to growth factor and hormone-controlled cellular regulation (Table 1).


Fig. 1. Gel image for the differential banding patterns obtained from bovine loin muscle in 12 (early fattening stage) and 27 month old (late fattening stage). The ACP DDRT-PCR products are separated on 1.5\% agarose gel and stained with ethidium bromide. GP1-20 indicated an arbitrary primer. Arrow indicated differentially expressed gene (G1-14) selected between early (12 month) and late fattening stages (27 month old). 
Table 1. Sequence similarity and characterization of differentially expressed genes

\begin{tabular}{|c|c|c|c|c|c|c|}
\hline $\begin{array}{l}\text { Clone } \\
\text { No }\end{array}$ & Function & $\begin{array}{c}\text { GenBank } \\
\text { Accession No }\end{array}$ & GenBank Homology (name) & $\begin{array}{l}\text { Fragment } \\
\text { size }\end{array}$ & E-value & $\begin{array}{l}\text { Expression } \\
\text { pattern }\end{array}$ \\
\hline G7 & Muscle structural protein & NM174225 & Actin, alpha1, skeletal muscle & $560 \mathrm{bp}$ & 0.0 & Down \\
\hline G14 & & X83957 & Nebulin & $650 \mathrm{bp}$ & 0.0 & Down \\
\hline G4 & & AY428575 & Telethonin & $750 \mathrm{bp}$ & 0.0 & Up \\
\hline G5 & & AJ012737 & Filamin, muscle isoform & $900 \mathrm{bp}$ & $3 e-49$ & Up \\
\hline G11 & & AB011673 & Desmin & $1.1 \mathrm{~kb}$ & 0.0 & Up \\
\hline G1 & Metabolism & BC102589 & Glyceraldehyde-3-phosphate dehydrogenase & $300 \mathrm{bp}$ & $3 e-118$ & Down \\
\hline $\mathrm{G} 2$ & & BC102263 & Cytochrome C oxidase polypeptide VIIc & $370 \mathrm{bp}$ & $5 e-154$ & Down \\
\hline G3 & & NM001013587 & Malate dehydrogenase 2 & $800 \mathrm{bp}$ & 0.0 & Up \\
\hline G8 & Signal pathway & NM214381 & Calcium/calmodulin-dependent protein kinase II & $550 \mathrm{bp}$ & 0.0 & Down \\
\hline G6 & & BTU88531 & Phosphatidyl inositol 4-kinase & $400 \mathrm{bp}$ & $1 e-120$ & Up \\
\hline G9 & Iron transport & AV528246 & Ferritin light polypeptide & $600 \mathrm{bp}$ & 0.0 & Up \\
\hline G12 & Membrane protein & XM600125 & Nidogen-2 precursor & $800 \mathrm{bp}$ & 0.0 & Up \\
\hline G13 & Extracellular proteinase inhibitor & XM589460 & WDNM1 protein precursor & $800 \mathrm{bp}$ & $1.4 \mathrm{e}-131$ & Up \\
\hline G10 & Transcriptional repressor & NM183060 & Induced cAMP early repressor & $300 \mathrm{bp}$ & 0.0 & Up \\
\hline
\end{tabular}

Quantitative real-time PCR confirmation of selected genes. To characterize the degree of adipocyte differentiation within the longissimus dorsi muscle, we analyzed the expression of the adipocyte-specific marker genes PPAR $\gamma$ and $\mathrm{C} / \mathrm{EBP} \alpha$ using RT-PCR. The mRNA expression of each gene was normalized by $18 \mathrm{~S}$ rRNA expression. The results of PPAR $\gamma$ and $\mathrm{C} / \mathrm{EBP} \alpha$ gene expression analysis are shown in Fig. 2. Although the PCR amplification showed considerable variation, $\mathrm{C} / \mathrm{EBP} \alpha$ and PPAR $\gamma$ expression levels in the late fattening stage ( 27 months old) were approximately eight-fold and three-fold higher than those measured in the early stage (12 months old), respectively (Fig. 2A). These results correspond with a report that adipocyte differentiation significantly increases between the early and late fattening stages (Lee et al., 2005).

We selected seven DEGs to confirm the efficacy of the ACP ddRT-PCR pre-screening. Sequence-specific primers were designed using the Primer3 program (http://frodo.wi.mit.edu/ cgi-bin/primer3/primer3_www.cgi) to amplify products ranging from 150 to 300 base pairs (Table 1). We isolated total RNA from the longissimus dorsi of Hanwoo steers at early and late fattening stages and performed quantitative RT-PCR for each of the seven selected DEGs. The results were consistent with the ACP ddRT-PCR prescreening (Fig. 2B). The mRNA expression of PI4-K, telethonin, ICER, ferritin, and WDNM1 were significantly higher at the late fattening stage compared to the early fattening stage in four pooled Hanwoo samples. Expression of phosphatidyl inositol kinase-4 (PI4-K) and inducible cAMP early repressor (ICER) in particular was significantly higher in the late fattening stage, whereas nebulin and calmodulin-dependent protein kinase II expression levels were slightly decreased.

Gene expression analysis during preadipocyte differentiation. We examined the expression patterns of seven selected genes in the early and late fattening stages. Using RT-PCR, we confirmed that ferritin, telethonin, WDNM 1, PI4-K, and ICER were highly expressed in the late fattening stage. It is possible that this observed difference in gene expression was due to the deposition of substantial adipose tissue in the longissimus dorsi muscle during the late fattening stage. Therefore, we confirmed the expression patterns of the selected genes during bovine preadipocyte differentiation using a bovine preadipocyte cell line. We analyzed the mRNA levels using the adipocyte cell type specific marker gene PPAR $\gamma$ to confirm the degree of bovine preadipocyte differentiation. The results indicated that PPAR $\gamma$ mRNA levels rapidly increased within the differentiation medium from day 2 to day 10 (Fig. 3A). Conversely, telethonin mRNA levels slightly decreased during preadipocyte differentiation (Fig. 3C). The ferritin gene was upregulated in the early differentiation stage, and further increased during preadipocyte differentiation (Fig. 3E). ICER and Cam KII mRNA levels gradually increased throughout the 10 days of adipocyte differentiation (Fig. 3D and F), whereas PI4K mRNA levels were variable (Fig. 3B), and no expression of the nebulin gene was detected in the preadipocyte cell line (data not shown). Increased expression of the ICER gene in particular may be due to the development of intramuscular fat within longissimus dorsi muscle during the late fattening stage. These results indicate that telethonin, ferritin, and PI4K may function in muscle growth rather than adipocyte differentiation, whereas ICER and Cam KII play important roles in adipocyte differentiation.

\section{Discussion}

This study was performed using the PCR based ddRT-PCR method, which can produce a high rate of false positives. Recently, a new annealing control primer (ACP) differential display PCR method was developed (Hwang et al. 2003; Kim 


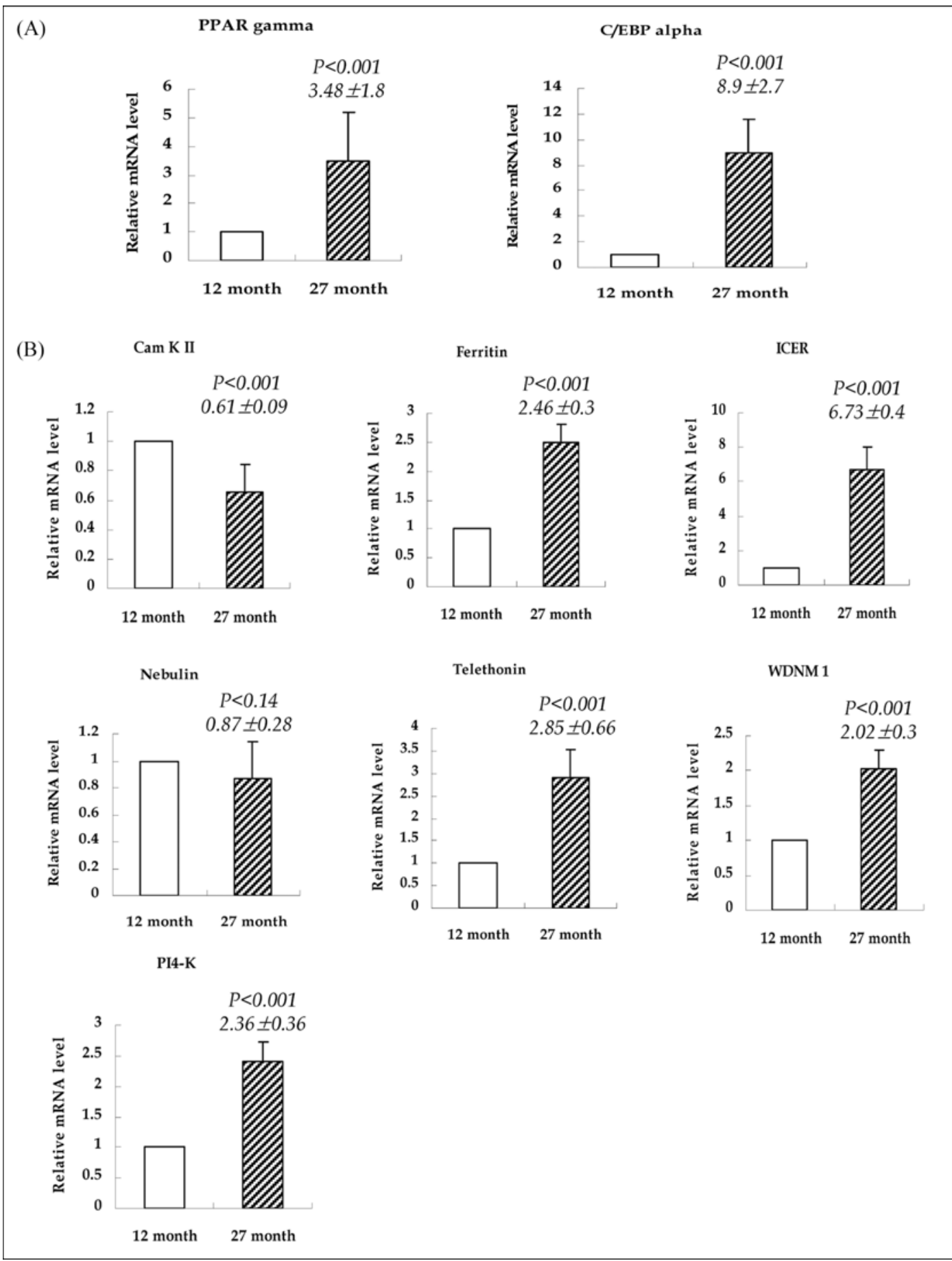

Fig. 2. (A) Real-time qRT-PCR analysis for $\mathrm{C} / \mathrm{EBP} \alpha$ and $\mathrm{PPAR} \gamma$ gene for the four pooled samples between early and late fattening stage of Hanwoo. (B) The relative mRNA levels of selected differential expressed genes using real-time quantitative RT-PCR in early (12 month old) and later fattening stage (27 month old) of Hanwoo steers. Real-time RT-PCR analysis for the four pooled samples were conducted three times and normalized using $18 \mathrm{~S}$ rRNA gene. Data are shown as means $\pm \mathrm{SD}$. Relative quantitation of gene expression is analysis using $\Delta \Delta \mathrm{C}_{\mathrm{T}}$ method. The $\mathrm{C}_{\mathrm{T}}$ value, threshold cycle. The $\Delta \mathrm{C}_{\mathrm{T}}$ value $=$ target gene $\mathrm{C}_{\mathrm{T}}-18 \mathrm{~S}$ ribosomal $\mathrm{C}_{\mathrm{T}}$; The $\Delta \Delta \mathrm{C}_{\mathrm{T}}$ value $=\Delta \mathrm{C}_{\mathrm{T}}$ value of 27 month old $-\Delta \mathrm{C}_{\mathrm{T}}$ value of 12 month old. Fold difference in the relative gene expression of target were calculated as $2^{-\Delta C \mathrm{CT}}$ value.

et al., 2004). Key to the ACP ddRT-PCR method is the unique tripartite structure of the specific primer, which has a $3^{\prime}$ end region with a target core nucleotide sequence, a 5'-end region with a nontarget universal nucleotide sequence, and a poly(dI) 


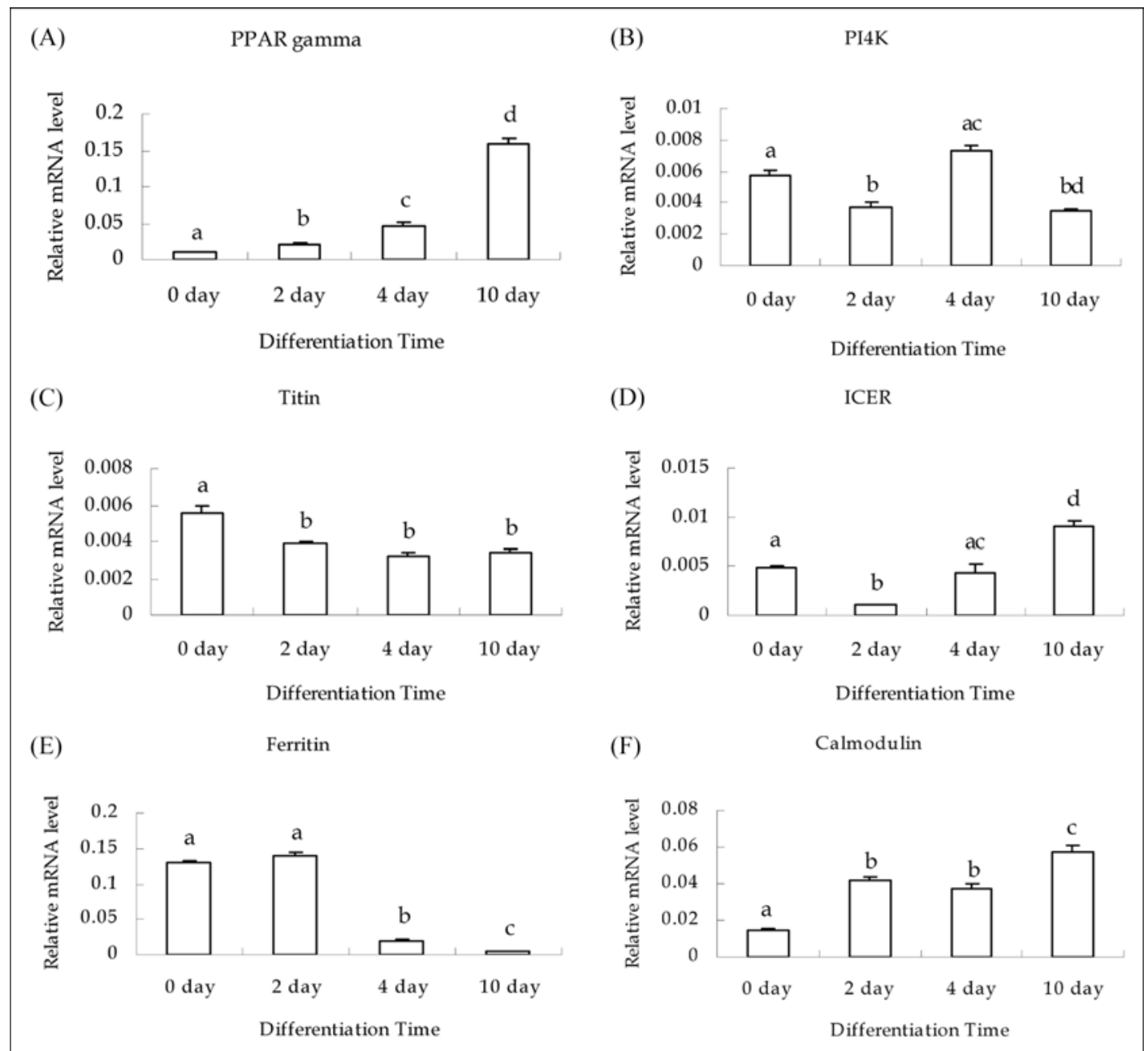

Fig. 3. Gene expression analysis of bovine preadipocytes cultured in the differentiation medium. The expression level of each gene was determined by real-time PCR as described in the Materials and Methods. Real-time RT-PCR analysis during the preadipocyte differentiation were conducted three times and normalized using $18 \mathrm{~S}$ rRNA gene. Data are shown as means $\pm \mathrm{SD}$. Relative quantitation of gene expression is analysis using $\Delta \mathrm{C}_{\mathrm{T}}$ method. The $\mathrm{C}_{\mathrm{T}}$ value, threshold cycle. The $\Delta \mathrm{C}_{\mathrm{T}}$ value $=$ target gene $\mathrm{C}_{\mathrm{T}}-18 \mathrm{~S}$ ribosomal $\mathrm{C}_{\mathrm{T}}$. Fold difference in the relative gene expression of target were calculated as $2^{-\Delta C T}$ value.

linker bridging the $3^{\prime}$ and $5^{\prime}$ end sequences (Hwang et al., 2003; Kim et al., 2004). These 5'-end nontarget and poly(dI) linker sequences do not interrupt nonspecific hybridization. Therefore, this method has a high reproducibility rate.

Using the ACP ddRT-PCR method, we found that the 14 genes involved in development of intramuscular fat between early and late fattening stages belonged to three biological categories: muscle and myofiber bundle development, metabolic pathways such as glycolysis and the TCA cycle, and growth factor regulated cellular signal transduction (Table 1). Telethonin, nebulin, filamin, desmin, and actin are associated with myofiber and muscle development. Nebulin is a giant protein of the cytoskeletal matrix that consists of the thick and thin filaments within the muscle sarcomeres and comprises 3 to $4 \%$ of the total myofibrillar protein (Stedman et al., 1988). Root and Wang (2001) suggested that nebulin plays a variety of roles in muscle sarcomeres and acts as a regulator of muscle contraction by inhibiting cross-bridge formation of thin filaments. Telethonin is also a sarcomeric protein and is involved in the reorganization of the cytoskeleton during myofibrillogenesis (Mayans et al., 1998). Nicholas et al. (2002) recently reported that telethonin functions as a regulator of myoblast differentiation by controlling levels of mature myostatin. Anderson (1992) reported that the loss of several myofibril proteins such as nebulin, telethonin, actin, filamin, and desmin caused the adipose mass in muscle to increase. Light et al. (1985) reported that the telethonin gene is involved in muscle connective tissue and plays an important role in determining meat toughness. We found that telethonin mRNA levels decreased slightly during preadipocyte differentiation (Fig. 3B). We therefore conclude that high expression of the telethonin gene in the late fattening stage is not a result of intramuscular fat development within the longissimus dorsi muscle. 
Table 2. Sequence-specific primer used for semi-quantitative and real-time RT-PCR confirmation of differentially expressed genes

\begin{tabular}{|c|c|c|c|}
\hline DNA band No. & & Primer sequence & Products size (bp) \\
\hline \multirow[t]{2}{*}{ G 4} & Forward & 5'-GAG TAC CAG CTG CCC TAC CA-3' & 374 \\
\hline & Reverse & 5'-AAC TCT GGG CGA ACT ACG AA-3' & \\
\hline \multirow[t]{2}{*}{ G 6} & Forward & 5'-GTG CAG TTC CCA GGA AGA AA-3' & 261 \\
\hline & Reverse & 5'-GCC AGT ACC CTC AGA TTG GA-3' & \\
\hline \multirow[t]{2}{*}{ G 8} & Forward & 5'-CAA TGC AGT CGG AAG AGA CA-3' & 305 \\
\hline & Reverse & 5'-CAA CTT CAT GCA CTC GGA AA-3' & \\
\hline \multirow[t]{2}{*}{ G 9} & Forward & 5'-TAA AAC CCA GGA CGC TAT GG-3' & 381 \\
\hline & Reverse & 5'-ATG GTC CAA GGC TTG AGA GA-3' & \\
\hline \multirow[t]{2}{*}{ G 10} & Forward & 5'-GGC ATT CAA GGA CAG CAA TA-3' & 193 \\
\hline & Reverse & 5'-GGG CAT CCA GCA GTA CAA TAA-3' & \\
\hline \multirow[t]{2}{*}{ G 13} & Forward & 5'-AAG GAG GCC AAG GTT CAT TT-3' & 307 \\
\hline & Reverse & 5'-GCA CAG CAG GGG TAG GTA TC-3' & \\
\hline \multirow[t]{2}{*}{ G 14} & Forward & 5'-GCA GAG CGA TGT CGA ATA CA-3' & 373 \\
\hline & Reverse & 5'-CAG GTC CTA TCC CTT CTT GC-3' & \\
\hline \multirow[t]{2}{*}{$\mathrm{C} / \mathrm{EBP} \alpha$} & Forward & 5'-TGG ACA AGA ACA GCA ACG AG-3' & 210 \\
\hline & Reverse & 5'-TTG TCA CTG GTC AGC TCC AG-3' & \\
\hline \multirow[t]{2}{*}{$\operatorname{PPAR} \gamma$} & Forward & 5'-CGA TAT CGA CCA ACT GAA CC-3' & 230 \\
\hline & Reverse & 5'-AAC GGT GAT TTG TCT GTC GT-3' & \\
\hline \multirow[t]{2}{*}{ 18S rRNA } & Forward & 5'-GAG AAA CGG CTA CCA CAT CC-3' & 300 \\
\hline & Reverse & 5'-GAC ACT CAG CTA AGA GCA TC-3' & \\
\hline
\end{tabular}

Glyceraldehyde-3-phosphate dehydrogenase (GPDH), cytochrome C oxidase polypeptide VIIc (COP VIIc), and malate dehydrogenase 2 (MDH-2) are involved in metabolic pathways. Weindruch et al. (2001) found that metabolic rates decreased in mouse muscle with aging. Conversely, it has been reported that caloric restriction was induced by the upregulation of glycolysis and gluconeogenesis (Weindruch et al., 2001). Our results indicate that the decreased expression of the GPDH and COP VIIc genes may be caused by the downregulation of metabolism due to a high energy diet in the late fattening stage.

Calcium/calmodulin-dependent protein kinase activity is regulated by intracellular calcium concentrations, which activate the expression of many genes that contain a cAMP response element (CRE) site in the regulatory region through the phosphorylation of CREB and CREM (Servillo et al., 2002). cAMP plays a key role in the regulation the adipogenesis during preadipocyte differentiation (Macdougald et al. 1995). Indeed, our data indicate that although calcium/calmodulindependent protein kinase (Cam KII) mRNA levels decreased in the late fattening stage, expression of Cam KII gradually increased during adipogenesis (Fig. 3D).

Casimir and Ntambi (1996) reported that intracellular cAMP activates the expression of the stearoyl-CoA desaturase gene, which is a key enzyme involved in monounsaturated fatty acid synthesis through the activation of the CRE binding protein. Here we demonstrated that the induced cAMP early repressor (ICER) gene was more highly expressed in the late fattening stage and showed a specific expression pattern in the longissimus dorsi muscle (data not shown). An in vitro study using a rat islet cell line showed that expression of the ICER gene was significantly increased by high glucose and free fatty acid treatment, and was associated with a reduction of insulin gene expression (Zhou et al., 2003). Conversely, ICER gene expression during bovine preadipocyte differentiation increased significantly from day 2 to day 10 (Fig. 3E). Therefore, the ICER gene may play a role in the regulation of intramuscular fat development within the bovine longissimus dorsi muscle. Interestingly, the genes encoding tyrosineamino-transferase (TAT), phosphoenolpyruvate carboxykinase (PEPCK), serine sehydratase (SDH), and glucose-6-phosphatase (G6P) contain CRE in their promoter region, and these genes are all essential for gluconeogenesis and are controlled by induced cAMP early repressor (Servillo et al., 2002).

In conclusion, we used a new ACP ddRT-PCR method and identified 14 differentially expressed genes between the early and late fattening stage of Hanwoo steers. In particular, we found that the inducible cAMP early repressor gene was significantly related to intramuscular fat development. Therefore, it is of interest to the cattle industry to determine the molecular mechanism of this gene by using selective gene inactivation techniques such as RNA interference in various animal cell lines.

Acknowledgments This work was partly supported by a grant (Code No. 200503 1034445) from Bio Green 21 Program, Rural Development Administration and awards from the International Collaboration research fund between the Rural Development Administration in Korea and the Co-operative Research Centre for Beef Genetic Technologies in Australia. 


\section{References}

Ailhaud, G.., Grimaldi, P. and Negrel, R. (1992) A molecular view of adipose tissue. Int. J. Obes. Relat. Metab. Disord. 2, 17-21.

Altschul, S. F., Gish, W., Miller, W., Myers, E. W. and Lipman, D. J. (1990) Basic local alignment search tool. J. Mol. Biol. 215, 403-410.

Anderson, M. S. and Kunkel, L. M. (1992) The molecular and biochemical basis of Duchenne muscular dystrophy. Traends Biochem. Sci. 17, 289-292.

Casimir, D. A. and Ntambi, J. M. (1996) cAMP activates the expression of stearoyl-CoA desaturase gene 1 during early preadipocyte differentiation. J. Biol. Chem. 270, 29847-29853.

Chawla, A., Schwarz, E. J., Dimaculangan, D. D. and Lazar, M. A. (1994) Peroxisome proliferator-activated receptor (PPAR) gamma: adipose-predominant expression and induction early in adipocyte differentiation. Endocrinology 135, 798-800.

Childs, K. D., Goad, D. W., Allan, M. F., Pomp, D., Krehbiel, C., Geisert, R. D., Morgan, J. B. and Malayer, J. R. (2002) Differential expression of NAT1 translational repressor during development of bovine intramuscular adipocytes. Physiol Genomics. 10, 49-56.

Hu, E., Tontonos, P. and Spiegelman, B. M. (1995) Transdifferentiation of myoblasts by the adipogenic transcription factor PPAR $\gamma$ and C/EBP $\alpha$. Proc. Natl. Acad. Sci. USA 92, 9856-9860.

Hwang, I. T., Kim, Y. J., Kim, S. H., Kwak, C. I., Gu, Y. Y. and Chun, J. Y. (2003) Annealing control primer system for improving specificity of PCR amplification. BioTechniques. 35, 1180-1184.

JMGA (1988) New beef carcass grading standards. Japan Meat Grading Association, Tokyo, Japan.

Kim, Y. J., Kwak, C. I., Gu, Y. Y., Hwang, I. T. and Chun, J. Y. (2004) Annealing control primer system for identification of differentially expressed genes on agarose gels. BioTechniques. 36, 424-434.

Konieczny, S. F. and Emerson, C. P. (1987) Complex regulation of the muscle-specific contractile protein (troponin I) gene. Mol. Cell. Biol. 7, 3065-3075.

Lee S. M, Jeoung, Y. H., Hwang, S. H., Park, H. Y., Yoon, D. H., Moon, S. J., Chung, E. R. and Kang, M. J. (2005) Differentiation of Hanwoo intramuscular preadipocytes. $J$. Anim. Sci. Technol. (kor) 47, 913-918.

MacDougald, O. A. and Lane, M. D. (1995) Adipocyte differentiation. When precursors are also regulators. Curr. Biol. 5, 618-621.

Mayans, O., van der Ven, P. F., Wilm, M. M. A., Young, P., Furst, D. O., Wilmanns, M. and Gautel, M. (1998) Structural basis for activation of the titin kinase domain during Myofibrillogenesis. Nature 395, 863-869.

Molina, C. A., Foulkes, N. S., Lalli, E. and Sassone-Corsi, P.
(1993) Inducibility and negative autoregulation of CREM: an alternative promoter directs the expression of ICER, an early response repressor. Cell. 75, 875-886.

Moody, W. G. and Cassens, R. G. (1968) Histochemical differentiation of red and white muscle fibers. J. Anim. Sci. 27, 961-968

Nicholas, G., Thomas, M., Langley, B., Somers, W., Patel, K., Kemp, C. F., Sharma, M. and Kambadur, R. (2002) Titin-cap associates with, and regulates secretion of, Myostatin. J. Cell. Physiol. 193, 120-131.

Nishimura, T., Hattori, A. and Takahashi, K. (1999) Structural changes in intramuscular connective tissue during the fattening of Japanese black cattle: effect of marbling on beef tenderization. J. Anim. Sci. 77, 93-104.

Paulin, D. and Li, Z. (2004) Desmin: a major intermediate filament protein essential for the structural integrity and function of muscle. Exp. Cell Res. 301, 1-7.

Pike, L. J. (2005) Phosphatidylinositol 4-kinases and the role of polyphosphoinositides in cellular regulation. Endocrine Rev. 13, 692-703.

Root, D. D. and Wang, K. (2001) High-affinity actin-binding Nebulin fragments influence the actoS1 complex. Biochemistry 40, 1171-1186.

Servillo, G., Fazia, M. A. D. and Sassone-Corsi, P. (2002) Coupling cAMP signaling to transcription in the liver: Pivotal role of CREB and CREM. Exp. Cell Res. 275, 143-153.

Stedman, H., Browning, K., Oliver, N., Oronzi-Scott, M., Fischbeck, K., Sarkar, S., Sylvester, J., Schmickel, R. and Wang, K. (1988) Nebulin cDNAs detect a 25-kilobase transcript in skeletal muscle and localize to human chromosome 2. Genomics 2, 1-7.

Tang, Q. Q. and Lane, M. D. (1999) Activation and centromeric localization of CCAAT/enhancer-binding proteins during the mitotic clonal expansion of adipocyte differentiation. Genes Dev. 13, 2231-2241.

USDA (1989) Official united states standards for grades of beef carcases. Agric. Marketing Serv. USDA, Washington, USA.

Wang, Y. H., Byrne, K. A., Reverter, A., Harper, G. S., Taniguchi, M., McWilliam, S. M., Mannen, H., Oyama, K. and Lehnert, S. A. (2005) Transcriptional profiling of skeletal muscle tissue from two breeds of cattle. Mamm Genome. 16, 201-210.

Weindruch, R., Kayo, T., Lee, C. K. and Prolla, T. A. (2001) Microarray Profiling of gene expression in aging and its alteration by caloric restriction in mice. J. Nutr. 131, 918-923.

Zhou, Y. P., Marlen, K., Palma, J. F., Schweitzer, A., Reilly, L., Gregoire, F. M., Xu, G. G., Blume, J. E. and Johnson, J. D. (2003) Overexpression of repressive cAMP response element modulators in high glucose and fatty acid-treated rat islets. A common mechanism for glucose toxicity and lipotoxicity?. $J$. Biol. Chem. 278, 51316-51323. 